\title{
Nessacities of Studying HSE Management Position and Role in Iran Oil Industry
}

\author{
Dana Mohammadnazar $^{\mathrm{a}, *}$, Amir Samimi ${ }^{\mathrm{b}}$ \\ ${ }^{a}$ Department of Polymer Chemistry, Shahreza Branch, Islamic Azad University, Shahreza, Iran \\ ${ }^{b}$ Department of Chemical Engineering, Mahshahr Branch, Islamic Azad University, Mahshahr, Iran
}

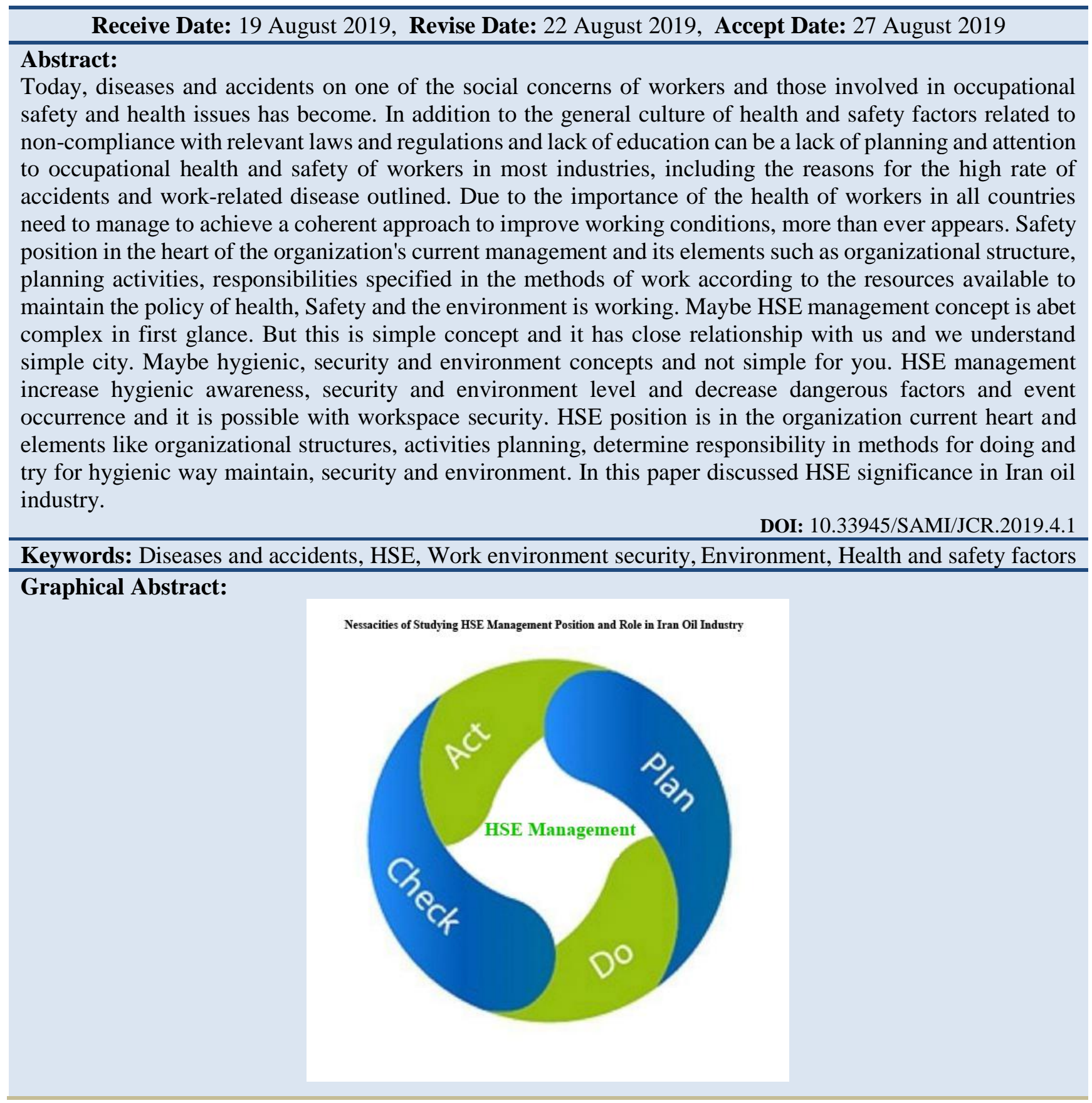

*Corresponding author: Dana Mohammadnazar, Email: dana.mnazar@gmail.com 


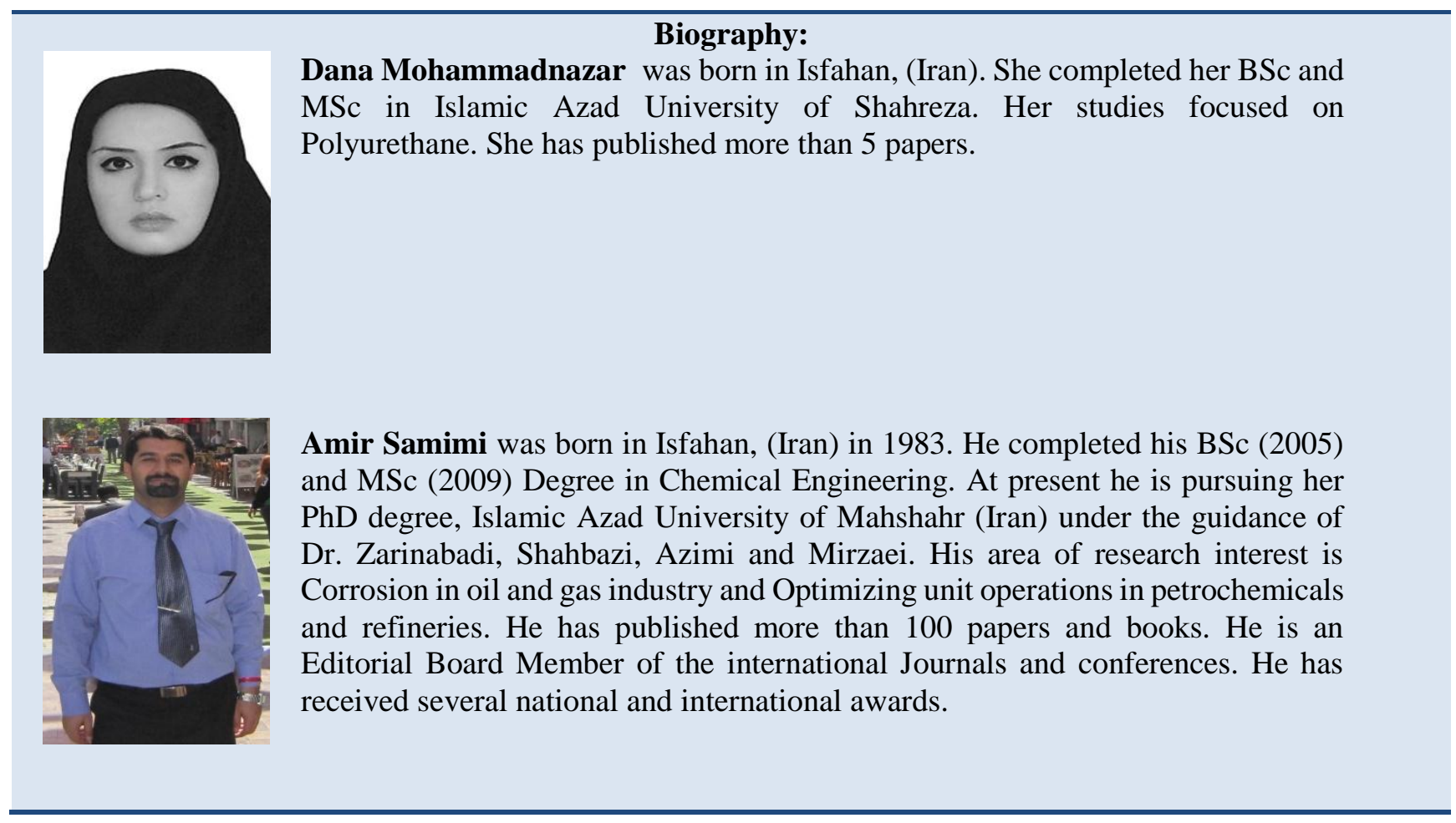

\section{Introduction}

Now, occupational diseases, accidents and incidental events are the social concerns for workers and the involvement of occupational health and safety issues has often seen in any industry. In addition to the general culture of health and safety factors related to noncompliance with relevant laws and regulations and lack of education can be a lack of planning and attention to occupational health and safety of workers in most industries, including the reasons for the high rate of accidents and work-related disease outlined. Due to the importance of the health of workers in all countries need to manage to achieve a coherent approach to improve working conditions, more than ever appears. Safety position in the heart of the organization's current management and its elements such as organizational structure, planning activities, responsibilities specified in the methods of work according to the resources available to maintain the policy of health, safety and the environment is working. Globally it has been shown that with the advancement of technology in societies, the health, safety and the environment of humans today are at high risk, and it is necessary to continue to consider these three categories more closely in order to continue human life [1-4]. The purpose of this paper is to examine the role and importance of health, safety and environment (HSE) in the oil and gas industry from different aspects and perspectives and emphasize the need for an integrated health, safety and environmental management system in these industries $[5,6]$.

The results of this study show that respecting and preserving the HSE is one of the principles of sustainable development of countries; the ultimate goal of each of these three issues is to preserve human health and human life, and taking these three issues together leads to more productivity; a management system health, safety, and the environment can be successful if it has a preventive approach to occupational accidents and environmental damage; as with any other management system, the proper culture of health safety $\&$ environment management system (HSEMS) leads to ease of implementation and efficiency; as contractors play an important role $[7,8]$. There are many oil and gas projects in the country, It is necessary to pay special attention to the HSE affairs of this worker group; in all oil companies in the world, attention to the issue of HSE is an inevitable priority, so that without the implementation of this management, the legitimacy of their activities is in fact questioned and necessary in the oil and gas industry [9]. The gas company of our country, with the modeling of this situation, has paid more attention to this matter than the past. The complex technological process and the extraction of human resources from natural resources have led to the neglect of the right of man, occupational health, society and the environment. And with the industrial revolution and the expansion of energy extraction from natural resources, the critical process to get an alert.

The process of the destruction of fires and explosions, the occurrence of widespread incidents, resulting in death or disability in workplaces, the various diseases resulting from activities in industrial environments, the destructive effects of the lack of industrial hygiene in the community, the widespread destruction of the environment, increased greenhouse gases (GHG) and 
damage to the protective layer of ozone. The spread of land to biological poverty, the expansion of nonrecyclable solid waste and wastage materials in nature, the increasing pollution in the vital ecosystems of the earth, and the sources of food production [10].

The survival of life and the preservation of the physical and mental health of man is the key to human life and the life of one's live. Therefore, the creation and development of appropriate structures for the preservation and development of health, the achievement of necessary safety and prevention of health and environmental damage is essential.

\section{Values position in management theories in oil industry}

Refineries, as one of the main sectors of the industry in Iran, are the leading supplier of value added in the oil and gas sector, which holds the bulk of the national and private capital of the country. Generally, financial losses are happened due to many incidental events happening in these factories. Irreparable, it raises the question of what is the main cause of such type's incidents:

the occurrence of several fires in the months and recent years in these industrial units as well as other oil and gas related industries caused a wave of sensitivity and concern in relationship to the quality and safety level of these units shows. In Iran's oil and gas industry, observance of safety precautions is neither in the construction sector, nor in maintenance scratch as it ought to be applied. It is also necessary to note that the issue of HSE compliance is not a specific to the oil and gas industry, but because of the high sensitivity of activity in this industry, the operations and observance of safety points in this sector is necessary [11]. There is a huge amount of national and private investment has been engaging in the oil industry and the special position of this industry in the country's economy is also critical of the high activity in this area because of the high incidence of accidents, observance of safety precautions should be aspect for all industries.

Organizational purpose has cultural and structural aspect and 2 aspects should change. Leadership methods are other management systems and affected by other values. Every society has its special values. Values are of the words that assign management books during current decades.

Several kinds of values are recognizable. Such as economical, moral, political, legal, cultural values and culture realized kind, level and values order. Culture gives identity to values. In other words values principle recognize by culture. There is mutual relationship between acceptable cultures and values, since values recognize. So they provide behavior and wishing models in society. My identity determine during values evaluation and present patterns. Values are systems of symbols and they organized in moral concert ideas relative to good or bad, proper or improper, correct or in corrector [12]. Values or concert and they generally have ability for applying them in different positions. But norms included acceptable behavioral standards in one group and its member contributed on it. He say us what we except in one certain scales and people behavior followed it. Indeed norms are systems of symbols that say people expect behaviors in certain situations and have mutual behavior. Today pay attention to workers healthy and entertainment issues and apply approaches for their body and moral situation considered as one score. So management role considered as one major factor for improve healthy level and organization environment and obtain to organization grow. The first place in professional hygienic management system is making trend. Usually trend approved by high order management and emphasize on commitment to these principles and this trend should include below cases:

A) Relative to hygienic risk of organization.

B) Include commitment to continue improvement and it include commitment to following professional hygienic laws and other obligations to organization.

C) It should be regular, apply able and constant and stated to all employees to day will be inform of hygienic, security obligations to be accessible to public and interest people and permanently evaluated to have their relation to others.

Management methods for recognize risks include below cases:

1- They defined with respect to activities filed too sure of method dynamic.

2- Ability for dividing risks and recognizes risks to remove or control these activities.

3- They should determine inputs for needs of organization and educational needs.

Partnership lager made society reproducible part and economy development is based on workface health and social development need to maintain their right (right for have body, moral and entertainment healthy) [13].

\section{Values and management}

If management considered as one system, values are in sub-systems and we discussed some of them: Organizational culture as one of the most management sub-systems has prominent position that values grow on it. We accept these principles are common values such as organizational culture elements and realized organizational believes and major values of organization that public pay attention to them are introducer of these culture and moral principles are value system that become pattern of organization members. And pay attention to this issue that organization culture consist of some common value 
that guide employees and reflected its result beside administer management methods, organization to human sources. Edgar shine said: (Cultural paradigm formed in security and determine why of think about their problems situations and their relation $s$ about them). He recognize different levels for culture as manifest that articulation are in first level and values are in second level. Also peter dranker believes organizations should have principles and values for themself. People values should match to organization values so person is efficiency and effective. Some people believes about change management that organization values systems determine properness level and they account values changes is nasality for every kind of organizational development. Every evolution is necessity for culture. In other words organizational evolution has two cultural and structural aspects.

\section{The three main phases to create safety in the industry}

The safety, health and environmental management system plays a role in preventing hazards in the three phases of prevention, control, pre-start and during emergency and after-incident action.

Phase of prevention: At this stage, potential issues of creating hazards are such that, with negative perceptions, the risks that may occur potentially and for any reason in the activities, along with the negative effects of that hazard in the factory or workplace environment, (please checked). And then examines the severity of the negative effects of risks, their likelihood of occurrence, and the type and amount of controls that are considered for that process and for the prevention of risks. In this way, according to the analysis, specific programs are defined as proposed actions to reduce the likelihood of occurrence of risk factors by creating new strategies, which will ultimately reduce the risks before the occurrence of the incident. To reduce the likelihood of a risk, it is better to reduce the likelihood of occurrence of hazards by defining precautionary measures and, in some way, modifying the effect and severity of the occurrence. Prevention phase is one of the most important phases in the HSE discussion. Which is addressed in clause 4 of this standard.

Control phase before and during the activity: In this phase, referred to in clause 6 of the standard, through control checklists all activities are monitored by the monitoring team. For example, metal scaffolding is used in the building industry. How to attach a scaffold has its own rules and conditions, for example, it has to be used with scaffolds whose components are of high quality (high-quality wooden parts with high and colorless fibers), the scaffolds are tightly restrained so that they move somewhere and does not slip, a suitable net or cover is installed on the lower floors, and all of the above mentioned issues, which are often difficult to resolve, are controlled by the HSE monitoring checklists and at all times of the operation, control gets the difference between phase 1 and 2 is in potential and the actual risks in activities. In the first phase, it has not yet happened, but it is likely to occur, but in the second phase, using the results of phase 1 and the use of records of risks that have already occurred or based on experiences, controls are placed that does not happen again. And under control.

Phase of emergency measures (after incident): In Phases 1 and 2 of the safety management system, the HSE, the responsible HSE groups, by defining preventive measures and controlling activities and potential hazards, are all endeavoring to make an accident for the organization does not happen during this time, if for any reason something happened in the organization, the safety management system, health, and environment has defined a program for that event to minimize the negative effects of that event in terms of physical, mental and financial. For example, if a worker is hurt during work, before he or she is taken to a hospital or before the presence of emergency and medical personnel on the premises, if important planning and initial medical assistance is planned for him and through the training person we can certainly reduce the negative effects of that happening. At this stage, we can easily do this by placing the first aid box and reducing the negative effects of the incident by using emergency plans during the incident [14]. The HSE at this stage tells us that emergencies, including work-related injuries, fire and fire, disease outbreaks, natural events, including the provision of first-aid medical equipment, fire extinguishing systems, the medical and pharmaceutical team, etc., and prepare the necessary preparations through periodic maneuvers. For example, teaching how to get out of danger or how to do relief and rescue operations.

\section{The reasons for HSE integration in the organization's management structure}

Quality and quality requirements, along with achieving an acceptable workflow, have been one of the most important issues in recent years in organizations. Advancement in the field of work and gaining market share, along with the achievement of concepts such as customer satisfaction, meeting legal and international requirements are among the most important factors encouraging organizations to move towards systematization of their activities. Meanwhile, there have been fundamental and undeniable international standards in the fields of environment and occupational safety and health as well as quality. The similarities between these management systems and the benefits of their simultaneous implementation have raised the 
issue of integrated management systems. The main driver of the emergence of the integrated management of health, safety and environment management (HSE) systems is shared among them. Integrating the safety, health and environment management system with the entire organization management system can facilitate the effective implementation of the HSE management system, as well as clarifying the duties and avoiding reorganization.

The HSE management system increases the value added for the organization's activities. The consequence of the HSE management system is to create a coherent process for achieving continuous improvement, with the scope and scope of this process being determined by the organization, with regard to economic aspects and other conditions. The HSE management system is a tool that the organization uses to achieve a level of safety, health, and environment performance that it has determined. Each organization has its own characteristics, facilities and requirements, and the organization itself is responsible for determining the boundaries of HSE management systems. The extent and complexity of HSE management systems, the volume of documentation and resources allocated to it, depends on the extent of the organization and the nature of its activities.

The question is: Is it necessary that the management systems be integrated seamlessly into the management of the organization? Some of the features and benefits of HSE integration in a single management are:

1. Avoiding re-work and costs.

2. Optimized use of resources and easier access to information.

\section{Reduce operating costs.}

4. Integrated HSE management approach is based on "prevention" that can be separated into three parts:

4.1. Prevention is based on the understanding and analysis of all processes of the organization.

4.2. Prevention based on the understanding and analysis of products.

4.3. Prevention is based on the analysis of information and figures derived from all safety, health and environmental events (whether resulting in or not adversely affected).

5. Establishing coordination between different parts of the engagement and preventing the failure of activities.

6. Applying possible comments due to different functions will be minimized.

7. By creating a comprehensive functional environment (in terms of occupational safety and health and the environment), it assists the organization's senior management in the strategic decision-making process that requires comprehension.

8. Reduces costs (audit fees, number of people involved with the implementation of the system, etc.) and reduces the volume of system documentation and records.

9. Reduce the cost of re-working.

10. Creating and expanding dynamic information flow in the system.

11. By establishing an integrated HSE management system, access to information becomes easier.

12. Define the goals of the micro and macro in a clear manner and in accordance with the organization's policy.

13. Avoid walking the wrong paths in moving towards the goals of the wise and the great. 14. Eliminating the interference and inconsistency of different mechanisms within the system.

15. Provide the possibility of system review and troubleshooting and weaknesses.

16. Provide feedback on the details of activities. 17. Providing background for various process forecasts.

18. Considering that standard performance is the "zero accident" for the best safety performance. 19. Planning and follow-up for the execution of the items outlined in the statement and the mission of the company.

20. Improving the quality of processes, products and services to increase customer satisfaction. 21 . Security systems and how to carry out activities to control and reduce HSE and operational hazards in units.

22. Compliance with environmental laws and regulations and occupational safety and health related to activities.

23. Compliance with HSE standards and product quality.

24. Respond to legal authorities and relevant organizations.

25. Auditing, registration and receipt of international certificates.

26. Follow up and planning to maintain HSE certificates.

27. Moving faster towards TQM's comprehensive quality management. 
28. Wide consistency between elements of health and safety management systems and environmental management.

29. Facilitate the provision of training to staff due to the structural similarity of the two systems. 30. There are common borders between $\mathrm{H} \& \mathrm{~S}$ and $\mathrm{E}$ $\& \mathrm{H}$ on the other.

Let's go back to the question originally raised, whether the integration of HSE in a single management, in other words, the implementation of IMS is a requirement or a recommendation. According to the above, each standard can exist alone and continue to work together. Establishing an IMS is not required, but due to the many benefits it provides and facilitates, accelerates and comprehensives the organization's HSE affairs, its guidance is provided by a single management unit $[15$, 16].

\section{HSE and its significance in oil industry}

Management system established in oil industry in 20/2/1990 and after acceptance of ministry success. Production, exploit, process and distribution process of oil \& Gas and produce petrochemical products follow extensive regulations in relation to hygiene and security. And all active companies has one certain strategy to provide their legal and operational obligations and security management system is one core of this strategy. Although there are important differences in administration level between security issue and environment, but security management standards and environment move toward model and they are for standard or security management system. Actions related to hygienic, security and environment has not coordination. So we provide one framework with pay attention to these issues to average technical and economic issues and remove the problems. Now $70 \%$ of industrial units in oil \& energy filed with respect to 70 years history use these systems. Technology and knowledge has 70 years history and this knowledge with respect to delay can have extensive position between country industry man and production authority [17].

We can say people awareness is increasing but the people in the past is not much familiar to the society and their applications in society and add value, but people. People and producers are aware with respect to present technologies due to many advantages, meet security management, hygienic and environment. And we hope to apply this system in different management and decrease costs- oil industry is pioneer industry in apply security management, hygienic and environment system. And then other related units act for establish this system in their units [18-20]. Now active companies in this field are very restrict and only $15^{*}$ companies in country activated relative to provide advisory services. And they should provide filed for extend these companies activities. Something include as consequences of establish hygienic management system, security and environment. Decrease losses due to events by:

$>$ Decrease loss due to stop work.

$>$ Decrease costs related to treatment and compensation pay level decrease of temporary disability or employees death.

$>$ Decrease environment loss and waste time decrease due to don't work people.

$>$ Decrease waste time due to cancers of subsidiary consequences.

Decrease plants repair or waste material and less waste in production.

\section{Conclusion}

Today, all countries have come to the conclusion that priority must be given to achieving sustainable development, human health, society and the environment. Fortunately, the allocation of the fifth and seventh seventh five-year plan for the development of the country to protect the environment and promote health and improve the quality of life also indicates the country's approach towards the HSE. In the course of economic development, in order to achieve sustainable and healthy development, a balance should be struck between health and professional health, and this is more to be considered in the process of country development planning. It should always be remembered that the three categories of health, safety and the environment have synergistic effects, and their simultaneous effect on the productivity of work is far more extensive and widespread. In the world, after World War II, the discussion has been combined with these three issues and has so far been dealt with in a serious way, so that the integrated implementation of HSE in a community is considered to be a sign of civilization and the level of culture of the people of the community. The lack of any of them can have a negative impact on the coherence of this integrated management system. Considering the pivotal role of health in the HSE topic and the fact that each of these three goals is to protect human health and human life, more attention is being paid to the field of health. A HSE management system in industrial environments can effectively achieve its goals, preventing accidents, reducing financial losses and injuries, protecting resources and the environment, and increasing productivity. For this reason, it is necessary to systematically identify and assess the risks of individuals, the environment and property, and their 
measures to reduce them; any action must be taken to protect the health of the workforce. Health risks are systematically evaluated in order to take appropriate measures. Personnel qualifications are regularly evaluated, followed by appropriate training programs. Any incident, pseudo-accident or unsafe condition must be reported in writing and analyzed, and appropriate action should be taken to prevent its recurrence. The experiences gained from this analysis will be systematically communicated to all operational units and used in preparation for future operations. In each activity, the implementation of the HSE policy is monitored periodically. When conducting audits, inhouse inspections and reviews, it is also necessary to assess the effectiveness of the HSE. In order to implement the HSE culture in an organization, it should set a certain value for it, strengthen the commitment of managers, and provide appropriate training courses for all levels of the organization. Considering the key role of contractors in carrying out the operations of the country's oil and gas industry, it is logical for corporate executives to focus on other aspects of management such as quality, economics, technology and production, management in their company's health, safety and environmental aspects. In particular, contractors should also be considered. The assessment and selection of contractors and employees should be made according to their efficiency in the field of HSE exploration and production. It is essential that their responsibilities in the field of HSE are explicitly explained in the contracts. Because improvement in the overall performance of the organization is not possible without addressing these aspects. The study of the experiences of the world's leading oil companies shows that investing in health, safety and the environment has a high priority, and the environmental issue is one of the permanent concerns in the exploration and production of all levels of the organization. Present of healthy force of body and moral aspect can considered as one potential investment during development trend. Although definite in technical hygienic set decrease of human sources efficiency and less field for human sources and provide filed for fall human potentials. So organization understand probably significance for professional and security hygienic and investment for then and use of healthy human forces.

\section{Acknowledgment}

The work presented in this paper is part of a research project of Amir Samimi (Ph.D. student in science in chemical engineering, Department of Chemical Engineering, Mahshahr Branch, Islamic Azad University, Mahshahr, Iran.

\section{References}

[1] Samimi, A., Zarinabadi, S., Kotanaei, A. H. S., Azimi, A., \& Mirzaei, M. (2019). Use of data mining in the corrosion classification of pipelines in catalytic reforming units (CRU), Iranian Chemical Communication, 7(5), 681-69.

[2] Bobtana, F., Elabbar, F., \& Bader, N. (2019). Evaluation of Halocnemum Strobilaceum and Hammada Scoparia Plants Performance for Contaminated Soil Phytoremediation. Journal of Medicinal and Chemical Sciences, 2(4), 126-129.

[3] Samimi, M., \& Samimi, A. (2012). Explotion of Resources Management in Iran. International Journal of Innovation and Applied Studies, 1(2), 232-235.

[4] Vassie, L., Tomàs, J. M., \& Oliver, A. (2000). Health and safety management in UK and Spanish SMEs: a comparative study. Journal of Safety Research, 31(1), 35-43.

[5] Alkherraz, A., Ali, A., Elsherif, K. (2020). Equilibrium and thermodynamic studies of $\mathrm{Pb}(\mathrm{II})$, $\mathrm{Zn}(\mathrm{II}), \quad \mathrm{Cu}(\mathrm{II})$ and $\mathrm{Cd}(\mathrm{II})$ adsorption onto mesembryanthemum activated carbon. Journal of Medicinal and Chemical Sciences, 3(Issue 1, pp. 194.), 1-10.

[6] Bradley, P. L., \& Baxter, A. (2002). Fires, explosions and related incidents at work in Great Britain in 1998/1999 and 1999/2000. Journal of loss prevention in the process industries, 15(5), 365-372.

[7] MArsAro, M. F., \& CAVAlCAnte, C. A. V. (2017). Random preventive maintenance policy based on inspection for a multicomponent system using simulation. Eksploatacja i Niezawodność, 19(4).

[8] McCabe, W. L., Smith, J. C., \& Harriott, P. (1993). Unit operations of chemical engineering (Vol. 1130). New York: McGraw-hill.

[9] Iranshahi, D., Karimi, M., Amiri, S., Jafari, M., Rafiei, R., \& Rahimpour, M. R. (2014). Modeling of naphtha reforming unit applying detailed description of kinetic in continuous catalytic regeneration process. Chemical Engineering Research and Design, 92(9), 1704-1727.

[10] Stijepovic, M. Z., Vojvodic-Ostojic, A., Milenkovic, I., \& Linke, P. (2009). Development of a kinetic model for catalytic reforming of naphtha and parameter estimation using industrial plant data. Energy \& Fuels, 23(2), 979-983.

[11] Gueddar, T., \& Dua, V. (2011). Disaggregation-aggregation based model reduction for refinery-wide optimization. Computers \& chemical engineering, 35(9), 1838-1856. 
[12] Arani, H. M., Shirvani, M., Safdarian, K., \& Dorostkar, E. (2009). Lumping procedure for a kinetic model of catalytic naphtha reforming. Brazilian Journal of Chemical Engineering, 26(4), 723-732.

[13] Shafiee, M. (2020). Recovering Gas Flares from the 12th Gas Phase of the South Pars Gas Refinery. Advanced Journal of Chemistry, Section A: Theoretical, Engineering and Applied Chemistry, 3(1), 49-57.

[14] Tremblay, J., Yergeau, E., Fortin, N., Cobanli, S., Elias, M., King, T. L., ... \& Greer, C. W. (2017). Chemical dispersants enhance the activity of oiland gas condensate-degrading marine bacteria. The ISME journal, 11(12), 2793.

[15] Song, C., Liu, H., Li, Y., Ge, S., Wang, H., Zhu, W., .. \& Li, H. (2014). Production of 5Hydroxymethylfurfural from Fructose in Ionic Liquid Efficiently Catalyzed by $\mathrm{Cr}$ (III)-A12O3 Catalyst. Chinese Journal of Chemistry, 32(5), 434-442.
[16] Gao, X., Shang, C., Jiang, Y., Huang, D., \& Chen, T. (2014). Refinery scheduling with varying crude: A deep belief network classification and multimodel approach. AIChE Journal, 60(7), 2525-2532.

[17] Moghadasi, Z. (2019). One-Pot synthesis of 2amino-4H-chromenes using L-Prolineas a reusable catalyst. Journal of Medicinal and Chemical Sciences, 2(1, pp. 1-49), 44-46.

[18] Nirmala, G. S., \& Muruganandam, L. (2019). Hydrodynamics in a Liquid Solid Circulating Fluidized Bed-A Review. Journal of Chemical Reviews, 1(2. pp. 78-170), 114-129.

[19] Heravi, M. M., Oskooie, H. A., Karimi, N., \& Hamidi, H. (2011). KAl (SO4) 2. 12H2O catalyzed efficient synthesis of 3, 4, 6-trisubstituted 2pyridone in water. Chinese Chemical Letters, 22(9), 1059-1062.

[20] Sajjadi, A., \& Moosavi, S. M. (2018). Synthesis of polymer-coated RDX/AP nanocomposites using supercritical CO2. Journal of Medicinal and Chemical Sciences, 1, 9-10.

How to cite this manuscript: Dana Mohammadnazar, Amir Samimi. Nessacities of Studying HSE Management Position and Role in Iran Oil Industry, Journal of Chemical Reviews, 2019, 1(4), 252-259. 